\title{
Epiblepharon with inverted eyelashes in Japanese children. II. Surgical repairs
}

\author{
SEIJI HAYASAKA, SACHIKO NODA, AND TOMOICHI SETOGAWA \\ From the Department of Ophthalmology, Shimane Medical University, Izumo, Japan
}

SUMMARY We used lid bracing sutures, buried sutures, and skin resection operations to correct epiblepharon in Japanese children. Epiblepharon and ocular irritation in 103 children (254 eyelids) were treated first with lid bracing sutures. Postoperatively the inversion of eyelashes resolved in 73 patients (196 eyelids). Of these 103 patients 30 (58 eyelids) developed recurrences, which included 11 who also complained of foreign body sensation and ocular pain. These 11 patients (22 eyelids) underwent a second surgical procedure (buried sutures or skin resection) before they became free of symptoms. No severe complications were noted in any of the 103 patients. We believe that lid bracing sutures correct most cases of mild epiblepharon in children and that buried sutures or skin resection are valuable for more severe conditions.

We have shown' that epiblepharon occurred commonly in Japanese infants but tended to disappear spontaneously with age. Only $2 \%$ of high school students in our series still had the condition. ${ }^{\prime}$ Although most children with epiblepharon had no or mild symptoms, some patients experiencing ocular pain needed treatment. These patients were treated initially with lid bracing sutures. If symptoms recurred, the patients underwent a second procedure, either with buried sutures or skin resection.

\section{Subjects and methods}

We selected for this study children who (1) underwent surgery for epiblepharon at Soma Municipal Hospital, Fukushima, and at Shimane Medical University Hospital, Shimane, (2) were examined at two and six months postoperatively, and (3) were followed up for a total of two years. Patients who could not be examined at one and two years were contacted by telephone. Those who underwent a second operation were observed for a minimum of two years.

An operation for epiblepharon was performed when children had an extra fold of eyelid skin, inwardly rotated eyelashes, corneal abrasion shown by staining with sodium fluorescein, and symptoms such as foreign body sensation and ocular pain. Parental agreement was obtained for all procedures.

Correspondence to Seiji Hayasaka, MD, Department of Ophthalmology, Shimane Medical University, Izumo, Shimane 693, Japan.
Surgery was not attempted in infants under 1 year of age.

Patients were treated initially with lid bracing sutures. If the inverted eyelashes, corneal abrasion, and symptoms recurred, they were treated again with buried sutures or skin resection. Most procedures were performed under local anaesthesia. Patients younger than 6 years or those who were fearful of having surgery underwent general anaesthesia. Both eyelids were treated as a rule, even in unilateral cases, to form symmetrical scars.

Simple lid bracing sutures were used to treat inferior epiblepharon. Double-armed sutures of 3-0 silk were brought from the inferior cul de sac, through the pretarsal orbicularis and out $3 \mathrm{~mm}$ below the eyelid margin. The arms of each suture were about $3 \mathrm{~mm}$ apart. Usually two sutures were placed at the medial and central portions of the lower eyelids and were tied tightly, with the beads forming a bolster to rotate the eyelashes outward. One week later the suture threads were removed.

For superior epiblepharon sutures were similarly passed from the superior cul de sac and out 3 to $4 \mathrm{~mm}$ above the eyelid margin. Most often three sutures were placed at the medial, central, and lateral parts of the upper eyelids. The suture threads were removed after one week.

Buried sutures were used as a second procedure. A double-armed 5-0 polyglycolic acid suture was passed in a similar way as the lid bracing suture. The conjunctival side of the entry site and the skin at the 
exit site were incised before suturing was performed. The sutures were tied tightly without a bolster, and buried. The wound of the skin was closed with sterilised tape. Buried sutures were not removed.

Skin resection was done in patients with large folds of eyelid skin. The semilunar-shaped fold of skin was excised, the wound was closed with 7-0 nylon, and the suture was removed after one week. To avoid ectropion postoperatively a minimal amount of skin was excised, resulting in the outward rotation of the eyelashes.

\section{Results}

Of 103 children ) 254 eyelids) older than 2 years of age who underwent surgery with lid-bracing sutures, 73 (196 eyelids) became free of symptoms. Recurrences developed in 30 patients ( 58 eyelids), even though 19 had not symptoms but had inverted eyelashes touching the cornea. Only 11 complained of foreign body sensation and ocular pain (Table 1). Recurrences were distributed among patients between 2 and 18 years of age.

Both lower eyelids and upper eyelids were treated at the first operation (Table 2 ). About $23 \%$ of eyelids treated had recurrences. No difference in predilection for right or left eyelids was noted.

Of the 103 children 14 showed a recurrence at two months' follow-up, 30 at six months after operation (Table 3). All second operations were performed within one year of the first.

Of the 11 patients who had symptoms after the first operation seven were treated with buried sutures and

Table 1 Recurrences after first lid bracing suture procedure for epiblepharon

\begin{tabular}{lllll}
\hline $\begin{array}{l}\text { Age at first } \\
\text { operation (yr) }\end{array}$ & Sex & $\begin{array}{l}\text { No. of } \\
\text { patients } \\
\text { treated }\end{array}$ & $\begin{array}{l}\text { No. of } \\
\text { patients with } \\
\text { recurrences* }\end{array}$ & $\begin{array}{l}\text { Percentage of } \\
\text { recurrences }\end{array}$ \\
\hline $2-3$ & M & 1 & 0 & 0 \\
& F & 6 & 3 & $50 \cdot 0$ \\
$4-6$ & M & 16 & $5(1)$ & $31 \cdot 3$ \\
& F & 17 & $6(1)$ & $35 \cdot 3$ \\
$7-9$ & M & 12 & $4(2)$ & $33 \cdot 3$ \\
$10-12$ & F & 15 & $4(1)$ & $26 \cdot 7$ \\
$13-15$ & M & 15 & $3(2)$ & $20 \cdot 0$ \\
& F & 11 & $3(2)$ & $27 \cdot 3$ \\
$16-18$ & F & 2 & 0 & 0 \\
& M & 4 & $1(1)$ & $25 \cdot 0$ \\
$0-18$ & F & 1 & 0 & 0 \\
& M & 3 & $1(1)$ & $33 \cdot 3$ \\
Total & F & 56 & $12(5)$ & $25 \cdot 5$ \\
& & 103 & $30(11)$ & $29 \cdot 1$ \\
\hline
\end{tabular}

*Recurrence was characterised by inverted eyelashes touching the cornea. Numbers in parentheses indicate patients complaining of symptoms. four underwent skin resection. All became symptomfree thereafter (Table 4). One patient who was treated with buried sutures was suspected of having an abscess two weeks postoperatively. After the sutures were removed, all signs of infection disappeared. Another patient who underwent a skin resection had a massive subcutaneous haemorrhage

Table 2 Eyelids treated with lid bracing sutures (103 patients)

\begin{tabular}{|c|c|c|c|}
\hline Eyelid & $\begin{array}{l}\text { No. of eyelids treated } \\
\text { at first operation }\end{array}$ & $\begin{array}{l}\text { No. of eyelids } \\
\text { with recurrences* }\end{array}$ & $\begin{array}{l}\text { Percentage of } \\
\text { recurrences }\end{array}$ \\
\hline \multicolumn{4}{|l|}{ Right: } \\
\hline Upper & 52 & 12 & 23 \\
\hline Lower & 73 & 17 & 23 \\
\hline \multicolumn{4}{|l|}{ Left: } \\
\hline Upper & 54 & 10 & $18 \cdot 5$ \\
\hline Lower & 75 & 19 & 25 \\
\hline Total & 254 & 58 & $22 \cdot 8$ \\
\hline
\end{tabular}

* Recurrence characterised by inverted eyelashes touching the cornea.

Table 3 Time of recurrence after first operation

\begin{tabular}{lll}
\hline Follow-up & $\begin{array}{l}\text { No. of patients } \\
\text { examined }\end{array}$ & $\begin{array}{l}\text { No. of patients } \\
\text { with recurrences* }\end{array}$ \\
\hline $2 \mathrm{mo}$ & 103 & 14 \\
$6 \mathrm{mo}$ & 103 & $30(7)$ \\
$1 \mathrm{yr}$ & $94 \dagger$ & $30(11)$ \\
$2 \mathrm{yr}$ & $91 \ddagger$ & $30(11)$ \\
\hline
\end{tabular}

* Recurrence characterised by inverted eyelashes touching the cornea. Numbers in parentheses indicate patients who underwent a second operation.

†One year after first operation: nine patients reported no symptoms via telephone inquiry.

$\ddagger$ Two years after first operation: 12 patients reported no symptoms via telephone inquiry.

Table 4 Incidence of recurrences and complications

\begin{tabular}{cll}
\hline Types of surgery & Recurrence and complications & $\begin{array}{c}\text { No. of patients } \\
\text { with recurrence } \\
\text { or complication }\end{array}$ \\
\hline Simple lid & None & 73 \\
bracing & Recurrence without symptoms & 19 \\
sutures & Recurrence with symptoms & 11 \\
$(\mathrm{n}=103)$ & Ectropion & 0 \\
& Cosmetic problem & 0 \\
Buried sutures & None & 6 \\
$(\mathrm{n}=7)$ & Recurrence without syptoms & 0 \\
& Recurrence with symptoms & 0 \\
& Suspected of having abscess & 1 \\
Skin resection & 0 \\
$(\mathrm{n}=4)$ & Cosmetic problem & 3 \\
& None & 0 \\
& Recurrence without symptoms & 0 \\
& Recurrence with symptoms & 1 \\
& Subcutaneous haemorrhage & 0 \\
& Ectropion & \\
\hline & Cosmetic problem &
\end{tabular}


that disappeared spontaneously after one month. Ectropion and cosmetic problems did not occur.

\section{Discussion}

The indications and methods of surgery for childhood epiblepharon are disputed, because all patients with inverted eyelashes do not have superficial keratitis, though the eyelashes touch the cornea. ${ }^{1}$ Moreover, children with epiblepharon and superficial keratitis do not always complain of foreign body sensation or ocular pain, and the condition usually disappears spontaneously with age. ${ }^{1}$ We therefore treated children older than 1 year who had, with epiblepharon, inwardly rotated eyelashes, superficial keratitis, and clinical symptoms.

No suture repairs were made in infants with epiblepharon who were younger than 1 year. If the infants had tearing or photophobia, the involved eyelids were pulled with adhesive tape to rotate the eyelashes outwards temporarily. One child with severe epiblepharon at age 20 months was treated by lid bracing sutures but was lost to follow-up.

Children with epiblepharon and symptoms who were older than 2 years were treated surgically. Lid bracing sutures were introduced for the correction of inferior entropion by Snellen. ${ }^{2}$ The procedure was modified by Komoto, ${ }^{3}$ and has been widely used to treat superior and inferior epiblepharons in Japan. ${ }^{4}$ Although this is one of the most frequent operations carried out by Japanese ophthalmologists, ${ }^{4}$ to our knowledge no results have been previously analysed. One advantage of lid bracing sutures is that the sutures are removed, reducing the risk of infection. Most of our patients (71\%) obtained good results from the procedure. Recurrence is one disadvantage of it. No complications, however, occurred in our series.

The method of buried sutures used in the present study was a modification of that described by Kato ${ }^{5}$ and by Quickert and associates. ${ }^{67}$ They used chromic gut sutures and did not incise the conjunctiva. We employed polyglycolic acid threads and incised the skin and conjunctiva to bury the sutures completely. No recurrences were observed in our patients postoperatively.

Skin resection, a method proposed by Celsus, ${ }^{2}$ may be commonly used to correct epiblepharon in Europe. ${ }^{8}$ This procedure generally has been contraindicated for childhood cases of epiblepharon in Japan ${ }^{49}$ though Tabuchi and Yamamoto ${ }^{10}$ recently reported good results for severe conditions. We used this procedure as a second operation to reduce large extra folds of eyelid skin. No recurrences or cases of ectropion were observed in our patients.

Patients with severe epiblepharon and epicanthus may benefit from Johnson's ${ }^{112} \mathrm{~V}-\mathrm{Y}$ plasty and skin excision. This procedure has been tried in some patients with epicanthus but was not used in the present study.

Our patients with mild epiblepharon obtained good results with lid bracing sutures. We believe that this procedure is useful in most affected Japanese children, and that buried sutures or skin resection is valuable for severe cases of epiblepharon.

\section{References}

1 Noda S, Hayasaka S, Setogawa T. Epiblepharon with inverted eyelashes in Japanese children. I. Incidence and symptoms. Br J Ophthalmol 1989; 73: 126-7.

2 King JH, Wadsworth JAC. Entropion. In: King JH, Wadsworth JAC, eds. An atlas of ophthalmic surgery. 2nd ed. Philadelphia: Lippincott, 1970: 48-75.

3 Cited by Kato K. Simple surgery for cutaneous entropion. In: Kato K, ed. Atlas of ophthalmic surgery. Tokyo: KaneharaShuppan, 1969: 441-4.

4 Ide A. Surgery for entropion and epiblepharon. In: Mizuno K, Nagata $\mathrm{M}$, eds. Color atlas of eye surgery, Part B. Tokyo: Medical-Byu, 1985: 216-23.

5 Kato K. Surgery for cutaneous entropion of the upper lid. In: Kato K, ed. Atlas of ophthalmic surgery. Tokyo: KaneharaShuppan, 1969: 445-50.

6 Quickert MH, Rathbun E. Suture repair of entropion. Arch Ophthalmol 1971; 85: 304-5.

7 Quickert MH, Wilkes DI, Dryden RM. Nonincisional correction of epiblepharon and congenital entropion. Arch Ophthalmol 1983; 101: 778-81.

8 Duke-Elder S. Epiblepharon. In: Duke-Elder S, ed. System of ophthalmology, London: Kimpton, 1964; 3: 857-9.

9 Hirose K. Entropium cutaneum (entropium ciliae cutaneum) and its surgical correction. Nippon Ganka Gakkai Zasshi 1940; 44: 1802-13.

10 Tabuchi A, Yamamoto M. Surgery (skin resection) for childhood inferior epiblepharon. Jpn Rev Clin Ophthalmol 1972; 66: 334-7.

11 Johnson CC. Epiblepharon. Am J Ophthalmol 1968; 66: 1172-5.

12 Johnson CC. Epicanthus and epiblepharon. Arch Ophthalmol 1978; 96: 1030-3.

Accepted for publication 28 January 1988. 